\title{
Comunicação social e vacinação
}

\section{Social communication and vaccination}

\author{
Cristina Maria Vieira da Rocha \\ Coordenadora de Vigilância à Saúde \\ Secretaria Estadual de Saúde de Alagoas \\ Rua Roberto Mascarenhas de Brito, 426, \\ apto. 601, bloco 2 \\ 57037-240 Maceió — AL Brasil \\ crisrocha@uol.com.br
}

ROCHA, C. M. V. da: 'Comunicação social e vacinação'. História, Ciências, Saúde — Manguinhos, vol. 10 (suplemento 2): 795-806, 2003.

As campanhas de imunização vêm passando, ao longo dos anos, por um processo de aperfeiçoamento, especialmente com o advento dos dias nacionais de vacinação contra a poliomielite, realizados a partir de 1980 . Há uma preocupação com o resultado do esforço em convocar pais e responsáveis por crianças menores de cinco anos. Várias estratégias são utilizadas. Foi criada uma marca que simbolizava, inicialmente, o compromisso com a erradicação da poliomielite e, posteriormente, com todas as vacinas previstas para o primeiro ano de vida. Foi o marco da comunicação que buscava dar unidade a esse processo sem perder as características mais localizadas. O Zé Gotinha é, até hoje, símbolo de vacina. Para além da polêmica sobre se campanha educa ou deseduca, fica o saldo positivo de uma experiência e a certeza de que é preciso buscar os motivos, continuar pesquisando, identificando metodologias e técnicas de maior aproximação com a população para que ela perceba a oferta de serviços e ações de saúde como direito de cidadania.

PALAVRAS-CHAVE: comunicação, campanhas, marca-símbolo, educação, Zé Gotinha.

ROCHA, C. M. V. da: 'Social communication and vaccination'. História, Ciências, Saúde-Manguinhos, vol. 10 (supplement 2): 795-806, 2003.

Over the years, various efforts have been made to improve immunization campaigns, especially through the 1980 introduction of National Vaccination Days against polio. Concern has been shown over the results of attempts to reach parents and others responsible for children under the age of five, and a variety of strategies have been tried. $A$ trademark was created in Brazil, at first symbolic of the commitment to eradicate polio and, later, linked to all vaccines that should be administered during the first year of a child's life. This use of communication tools represents an endeavor to lend unity to the process without overriding local characteristics. Even today, Zé Gotinha symbolizes vaccines in Brazil. Leaving aside the controversy over whether campaigns inform or disinform, the experience has left its positive mark, clearly showing us it is necessary to explore motivations, advance research, and identify methodologies and techniques that will reach the general public and help people perceive that health services and activities are a citizen's right.

KEYWORDS: communication, campaigns, trademark, symbol, education, Zé Gotinha.

...o bomem não é igual a nenhum outro bomem, bicho ou coisa.

Não é igual a nada.

Todo ser bumano é um estranho impar.

Carlos Drummond de Andrade (1980)

Z screver sobre o papel da comunicação social nas campanhas E de vacinação é voltar no tempo, ao final das décadas de 1970 e 1980, para resgatar registros e um pouco da experiência de informar sobre saúde e, mais especificamente, sobre vacinas. 
Na verdade, a utilização do instrumental da comunicação remonta à década de 1920, quando formalmente se propôs associar a propaganda na educação da população com a finalidade de modificar conhecimentos e atitudes, tendo em vista a adoção de comportamentos favoráveis. Nos seus primórdios, o enfoque era fiscal e policialesco. Depois, as mudanças de comportamento foram relacionadas a exigências do desenvolvimento, à superação do atraso, à busca do moderno. O sanitarismo, de inspiração militarista, propõe combater doenças de massa mediante a "criação de estruturas ad hoc, com forte concentração de decisões e com um estilo repressivo de intervenção sobre os corpos individual e social" (Mendes, 1992). Com a industrialização e a urbanização da economia, o objetivo é "atuar sobre o corpo do trabalhador, mantendo e restaurando sua capacidade produtiva". Esvazia-se o campanhismo e surge o modelo médico-assistencial privatista.

As campanhas de saúde pública desenvolvidas pelos sanitaristas no início do século XX eram encaradas com muita desconfiança pela população. A forte carga de rejeição que inspiravam fez surgir movimentos como a conhecida Revolta da Vacina. Tais reações foram decorrentes, principalmente, da abordagem coercitiva baseada em leis e decisões que iam de encontro aos direitos de cidadania. Foi um período em que imperou o medo. Medo das reações provocadas pela vacina antivariólica, medo do isolamento imposto aos doentes e seus contatos. A população se escondia, escondia seus doentes. O trabalho era feito casa a casa, residências eram invadidas pela polícia sanitária, explicitando o abuso do poder (Teixeira, 1999).

Nas décadas de 1920 e 1930, o rádio e o cinema consolidaram-se como instrumentos de propaganda política. $\mathrm{Na}$ área da saúde, a propaganda buscou influenciar e ajustar as pessoas a normas e prioridades definidas epidemiologicamente, utilizando como recursos acessórios o reconhecimento de crendices e superstições, bem como o conhecimento sobre transmissão de doenças. São, da mesma forma, reconhecidas e abordadas as lideranças locais, os veículos de comunicação existentes, as igrejas e escolas. Os planos de ação incluem estratégias de persuasão com a finalidade de 'levar' os indivíduos a cumprirem as recomendações estabelecidas pelas autoridades sanitárias. Era, conforme Pitta (1995), "o ideário tradicional da educação sanitária".

Educar para a saúde, com a finalidade de prevenir doenças ou ensinar hábitos de higiene, é preocupação que se intensifica no início da década de 1940, quando surgem instituições federais voltadas exclusivamente para a saúde pública e para o controle das endemias rurais. Carlos Sá (1934) afirmava a importância de "difundir no público em geral os conhecimentos necessários à melhoria do comportamento sadio".

Na década de 1950, segundo Bordenave (1981), não se falava muito de comunicação, mas de informação. A função dos especialistas 
era "difundir, de maneira persuasiva, novas tecnologias e produtos ... para receptores supostamente passivos". Depois o conceito de comunicação foi ampliado de modo a incluir maior grau de diálogo e participação entre os dois pólos do processo. Nessa perspectiva, "os meios de comunicação, antes usados como canais de informação e veículos de persuasão, passam a ser empregados como ferramentas de diagnóstico da problemática social, de colocação de problemas, de aglutinação comunitária, de auto-expressão individual e coletiva, de interaprendizagem, de negociação e reivindicação".

Na década de 1970, citando ainda Pitta (1995), as inovações incluem o ajuste da linguagem à população-alvo, "uma forma de conferir mais eficácia aos procedimentos de transferência de informações a indivíduos ou grupos sociais". O objetivo de educadores e sanitaristas é modificar comportamentos individuais e coletivos, buscando a incorporação de hábitos e práticas de promoção e manutenção da saúde. Como paradigma sanitário derivado da concepção monocausal das doenças, o sanitarismo sustentava a necessidade de interpor barreiras comportamentos individuais e coletivos - para impedir a relação entre causa e efeito (Mendes, 1992). Tal visão, que leva a modelos explicativos restritivos, reforça "respostas unilaterais marcadas por uma visão clínica e que se localizam no espaço de atenção às pessoas".

Na Universidade de São Paulo (USP), em 1973, época em que fiz o curso de educação em saúde pública, esses aspectos tinham enfoque de peso: no estágio profissional, nós, os educadores, éramos encarregados de identificar lideranças e organizações da comunidade, hábitos e costumes contrários à saúde; no estágio que fiz, avaliei a compreensão de pais e responsáveis por escolares sobre vacinação, abordando componente da educação em saúde bastante valorizado à época: a saúde escolar.

O Programa Nacional de Imunizações (PNI), também instituído em 1973, preconizava o diálogo com pais e responsáveis por todas as crianças menores de um ano, alvo das vacinas ofertadas nos serviços públicos de saúde. A informação e mobilização das comunidades deveriam ter como propósito "assegurar a adesão informada da população ao programa".

A partir da segunda metade da década de 1970, o discurso oficial incorporou a participação comunitária, pois era "preciso diminuir e aliviar as tensões sociais geradas pelo modelo econômico e pela crise que se inicia com o fim do 'milagre'. O sistema se vê obrigado a abrir algumas brechas" (Cardoso de Melo, 1981).

Os programas de saúde adotaram a participação comunitária como estratégia de atuação, e o tema passou a figurar em toda discussão mais geral sobre saúde, na efervescência da VIII Conferência Nacional de Saúde, em 1986. Não se concebia democratização da saúde sem participação da população nos processos de decisão e na implementação destas decisões. A participação, no entanto, virou panacéia, fazendo 
com que surgissem posicionamentos críticos, como o do diretor da Organização Pan-Americana de Saúde (OPAS), Carlyle Macedo (1984), no discurso sobre 'Saúde nas Américas, perspectivas para o ano 2000':

não esta participação instrumental, não esta participação-objeto, nem tampouco essa participação teórica, de certa maneira anárquica, que confunde democracia com democratismo, que imobiliza o processo de gerência com a condução por todos através da discussão interminável. Mas a participação efetiva: o estabelecimento de mecanismos que permitam que todas as pessoas interessadas, em todos os níveis, possam demonstrar, de alguma maneira, suas necessidades e sua percepção de como essas necessidades devem ser satisfeitas.

É nesse contexto que se consolida a estratégia de vacinação em massa contra a poliomielite, cuja situação epidemiológica era considerada extremamente grave, "impossível de ser modificada a curto prazo, em virtude da insuficiência da rede de serviços básicos de saúde para proceder rotineiramente à vacinação sistemática da população suscetível" (Ministério da Saúde, 1988). A proposta de mudança de estratégia baseava-se na facilidade de aplicação da vacina oral, o que permitiria utilizar o recurso ao voluntariado de forma intensiva.

O processo foi desencadeado. Epidemiologistas e educadores, em duplas, passaram a percorrer o país, para realizar um trabalho de 'convencimento' das equipes responsáveis por vacinação e vigilância epidemiológica, bem como de dirigentes estaduais e municipais de saúde, quanto à viabilidade da proposta: aumentar significativamente a cobertura vacinal da população suscetível (menores de cinco anos) através de dois dias nacionais de vacinação. Fiz parte dessas duplas e participei ativamente da estruturação dos chamados dias nacionais de vacinação.

Foram organizados, no Ministério da Saúde e nos estados, liderados pelas secretarias estaduais de Saúde, grupos interinstitucionais para cuidar dos diferentes aspectos do trabalho: clínico-epidemiológico, recursos humanos, logística, divulgação e mobilização da população. Profissionais das áreas de educação e comunicação, representantes de instituições diversas, bem como de organizações e grupos da comunidade participavam de encontros de discussão, definindo estratégias de ação que pudessem levar a vacina o mais próximo possível do grupo-alvo. Técnicos da Fundação SESP e da Sucam debruçavam-se sobre mapas e lançavam mão do chamado reconhecimento geográfico (RG) para traçarem os roteiros de equipes volantes aos pontos mais longínquos, acessiveis após vários dias de viagem nem sempre confortáveis — a pé, em lombo de burros ou em carroças, barcos, canoas, bicicletas e aviões. A experiência da Campanha de Erradicação da Varíola foi muito importante, mas já não estava disponível o exército de vacinadores. O momento era outro, e outra, a necessidade de trabalho articulado entre 
Ministério da Saúde, estados e municípios, com efetiva participação da sociedade.

$\mathrm{Na}$ área de comunicação houve grande movimentação. Os educadores que iam aos estados levavam uma série de sugestões para mobilizar a população. Nas discussões localizadas, fervilhavam idéias quanto ao uso de veículos locais de comunicação e estratégias específicas para sensibilizar pais e responsáveis por menores de cinco anos. As comissões de divulgação e mobilização eram integradas por representantes da comunicação social, da educação e cultura, grupos religiosos, clubes de serviços - como Rotary e Lyons -, além de associações de classe, profissionais, sindicatos de jornalistas, publicitários e relações-públicas, representantes de veículos de comunicação - jornais, emissoras de rádio e televisão, serviços de alto-falantes, rádios comunitárias —, o comércio e a indústria.

Nas reuniões nacionais promovidas para avaliar e definir rumos havia, inclusive, certo espírito de competição entre as secretarias estaduais, na distribuição de cartazes, folders, panfletos, camisetas etc. Em nível nacional, pode-se afirmar que os dias de vacinação foram úteis, especialmente para consolidar uma cultura de comunicação de massa em saúde feita, inicialmente, de forma meio amadorística não no sentido da concepção, mas em termos de infra-estrutura. Na época, a área de comunicação social era uma unidade gestora sem verbas próprias, ligada diretamente ao ministro da Saúde. Foi incumbida de "fazer a mobilização nacional para a vacinação maciça da população, atividade que veio a se tornar prática comum nos anos que se seguiram" (Ministério da Saúde, 1996). Posteriormente, a área foi profissionalizada, com o ingresso de agências de publicidade, utilizando-se, no trabalho de mobilização, figuras reconhecidas em todo o país, como atores, humoristas, jogadores de futebol etc.

A retrospectiva das campanhas mostra que houve uma evolução no processo de comunicação no âmbito da saúde. Gradativamente, o apelo inicial ao medo, à culpa, à exclusiva responsabilização dos pais e à exploração de imagens de crianças com deficiências físicas graves, usando cadeiras de rodas ou aparelhos ortopédicos, deram lugar ao apelo à responsabilidade individual e coletiva em garantir a vacina para as crianças. A vacinação é defendida como um ato de amor, além de direito da criança: "mãe, que é mãe, vacina"; "uma nova dose de amor"; "dobre seu compromisso"; "comprometa-se com a vacina" (Teixeira, 1999).

Toda essa movimentação, que envolveu epidemiologistas, educadores e comunicadores, provocou reações dentro e fora do Ministério da Saúde. Reações dos que defendiam as ações de rotina nos serviços de saúde e dos que criticavam o verticalismo e o ressurgimento do espírito de campanha nos dias nacionais de vacinação. Para muitos, "ações pontuais deseducariam a população, pois representavam uma contraposição às ações de rotina" (Ministério 
da Saúde, 1996). Em 1981, a Divisão Nacional de Educação em Saúde buscou um meio-termo nessa polêmica. Propôs diretrizes à ação educativa em saúde, usando uma situação de baixa cobertura em imunizações como exemplo para ilustrar as etapas do processo participativo. Alertou, no entanto, para o fato de que "a programação da ação educativa deve ser abrangente, visando uma compreensão mais global da situação de saúde da população" (Ministério da Saúde, 1981).

Essa preocupação com a abrangência da ação educativa fez surgir várias iniciativas. Projeto de 1982, que não se sabe se foi concretizado, pretendia "conhecer a percepção da população sobre as doenças evitáveis por vacinas", apontando as baixas coberturas de vacinação na rotina e a necessidade de divulgação das ações de imunização, uma vez que "a população desconhece a importância e os tipos de vacina disponíveis" (Ministério da Saúde, 1982). O projeto reconhecia que tinham sido grandes os esforços para divulgar, através dos meios de comunicação de massa, mais informações sobre vacinas; que muito material educativo fora produzido; e que a maioria dos currículos de primeiro e segundo graus já incluía a imunização nos conteúdos de ciências e programas de saúde. Em vista disso, era preciso saber em que medida as informações estavam "influenciando o comportamento da população em relação às doenças transmissíveis evitáveis por imunizantes".

Uma proposta do Ministério da Saúde, também de 1982, buscava incorporar a ação educativa às atividades de prevenção e controle de doenças transmissíveis, permitindo "aos profissionais de saúde, às instituições, grupos e lideranças, como à população em geral, uma participação consciente, reconhecendo a importância dessas atividades, especialmente as de vigilância epidemiológica e de imunizações, para a melhoria das condições de saúde da comunidade" (Ministério da Saúde, 1982). Afirmava-se ainda que "os melhores e mais modernos métodos de prevenção, controle e erradicação de doenças podem estar destinados ao fracasso se não contarem, em sua aplicação, com a compreensão, o apoio e a participação da população".

Em maio de 1985, a OPAS conclamava os países da região a unirem esforços visando erradicar a transmissão autóctone do poliovírus selvagem no hemisfério até 1990. O diretor da organização, em pronunciamento, declarou "ser inaceitável que qualquer criança das Américas sofra de poliomielite", salientando que esse esforço "será o veículo que canalizará todas as nações do hemisfério a alcançarem os objetivos de cobertura universal de vacinação contras as doenças da infância até o final da década" (Ministério da Saúde, 1988).

A decisão foi abraçada pelo Brasil, onde mudanças significativas no comportamento epidemiológico da poliomielite vinham ocorrendo: $\mathrm{O}$ número de casos aumentava, mudando o tipo de vírus predominante. 
As coberturas de vacinação nos dias nacionais reduziam-se, talvez por acomodação dos setores envolvidos devido à crença de que as equipes já sabiam o que fazer e de que a população estava já consciente. Outra explicação para a redução das coberturas foi a introdução, em 1984, das vacinas injetáveis. Em alguns estados, aproveitando a mobilização da população, foram administradas, concomitante e seletivamente, a vacina tríplice e a vacina contra o sarampo. "A estratégia foi abandonada por ter sido apontada como responsável pela queda nas coberturas da vacina contra a poliomielite" (Ministério da Saúde, 1998).

Com a proposta de erradicação, foram adotadas várias iniciativas. O progresso no controle da doença fez com que muitos clínicos deixassem de considerar a poliomielite como parte do diagnóstico diferencial nas paralisias de início súbito, buscando outras hipóteses. Em função disso, a capacitação de médicos foi incrementada. Implementou-se, também, o diagnóstico laboratorial. As estratégias de vacinação foram repensadas, retomando-se o bloqueio de surtos. Todo caso suspeito devia ser investigado em 48 horas. Informe epidemiológico específico passou a ser editado, divulgando semanalmente dados atualizados sobre a ocorrência da doença e sobre as atividades de erradicação. Em Brasilia, realizou-se reunião nacional, com ampla representatividade institucional, para discutir a erradicação da transmissão da poliomielite no Brasil, criando-se um grupo técnico para coordenar as atividades pertinentes à erradicação - o GT/Pólio. Ainda nesse ano, foi introduzido o dia nordestino de vacinação contra a poliomielite, mantido até 1993. Em 1987, a formulação da vacina oral contra a poliomielite foi alterada, aumentando-se a concentração do poliovírus tipo 3.

No campo da divulgação e comunicação, também aconteceram mudanças significativas. A principal foi a criação de uma marca da erradicação da poliomielite, apontando-se como vantagem "a manutenção da unidade das atividades de comunicação ao longo de todo o tempo que perdurar o plano" (Ministério da Saúde, 1986). Outra vantagem apontada era de natureza econômica, em decorrência do uso de comunicação mais localizada: seriam confeccionados fotolitos das matrizes de várias peças para que fossem introduzidas mensagens e ilustrações que estivessem mais de acordo com cada realidade.

Os criadores da logomarca optaram por lembrar às pessoas a importância de preservar nas crianças o direito de andar, baseados na premissa de que

não existe castigo maior para uma criança do que ser privada da liberdade de correr, andar, subir e descer de árvores, jogar bola, brincar. Esse constante ir-e-vir é o estímulo para que ela sinta e apreenda o mundo em que vive, retirando dele o seu aprendizado de vida, de forma livre e criativa. A poliomielite representa, principalmente para a criança, uma ameaça constante de perda dessa liberdade física e espiritual (Ministério da Saúde, 1986). 
A marca proposta foi baseada em estudo fotográfico de 1887, de Eadweard Muybridge, que foi simplificado e transformado em desenho.

\begin{abstract}
A este foram acrescidas as duas gotas necessárias à vacinação, bem como o cronograma do compromisso brasileiro de erradicar a poliomielite, representado pelos anos e pelo diferenciado tratamento de cor das figuras, passo a passo, ano a ano ... a criança do desenho foi transformada em um boneco, cuja cabeça lembra uma gotinha da vacina (Ministério da Saúde, 1986).
\end{abstract}

No entanto, as críticas às campanhas e à proposta de erradicação persistiam. Os responsáveis pela condução do trabalho eram chamados de a "turma da vacina", mas não havia como retroceder diante de uma experiência consolidada e que cada vez mais contribuía para o fortalecimento da vigilância epidemiológica e do controle de doenças em nível nacional.

Foi estabelecido nesse período o Projeto de Divulgação para o Programa de Imunizações, que incluía a proposta de ampliação da marca da erradicação da poliomielite para a marca do PNI. Como o boneco da poliomielite nascera e precisava ganhar identidade, surgiu a idéia de um concurso nacional para a escolha de seu nome: "além de popularizar o símbolo, foi uma oportunidade para promover uma mobilização nacional e uma participação mais efetiva em torno do tema vacinação. Na divulgação do evento foi usado, como peça básica, um filme que contava a história do nascimento do boneco, personalizando-o" (Ministério da Saúde, 1988). Feito o concurso, com a participação de escolares de todo país, e com prévia escolha de nome para cada estado, um júri em nível nacional escolheu 'Zé Gotinha'. Logo em seguida, o boneco foi utilizado no filmete para o dia nordestino de vacinação, caracterizado como cangaceiro.

O Zé Gotinha firma-se como sinônimo de vacina, e como "referencial para a população, em termos de métodos de prevenção, principalmente os referentes às doenças evitáveis por vacinação ... a proposta da marca englobaria, além da vacinação, as demais ações básicas de saúde da criança: crescimento e desenvolvimento, reidratação oral, aleitamento materno" (Ministério da Saúde, 1988). Entretanto, até que houvesse aceitação de seu uso em nível nacional, "decidiu-se que, inicialmente, a marca seria trabalhada para as vacinas do primeiro ano de vida ... Em conseqüência, foi criado um símbolo para o PNI, formado por uma ciranda de seis bonequinhos", seis 'Zés Gotinhas' representando as seis vacinas do primeiro ano de vida, "diferenciados por cores, que, nas peças com animação, vão aparecendo um a um, numa ordem cronológica, segundo o esquema básico de aplicação das vacinas". O bonequinho, nessa nova fase, quando em ação, é multiforme, "sendo capaz, dependendo das circunstâncias, de assumir qualquer forma para combater os agentes causadores das doenças". São montadas 
histórias mostrando o Zé Gotinha junto a amigos e à comunidade. O perfil do personagem é traçado tendo como parâmetro o "mito do herói": é simples, tem força sobre-humana, luta triunfante contra o mal. Seus inimigos são os agentes causadores de doenças; o conceito do bem e do mal abre "espaço para, didaticamente, explicar a programação das vacinas". Os principais amigos fazem parte de "uma família constituída de pai, mãe, dois filhos, cachorro, gato e uma equipe de saúde" (Ministério da Saúde, 1988).

Em 1987, ainda no campo da comunicação, há todo um investimento no resgate de formas de comunicação mais locais, e de acordo com as características das populações, a partir de oficinas de técnicas alternativas e artesanais, capacitando-se pessoas das comunidades para a produção de material de divulgação, inclusive teatro de bonecos, literatura de cordel e repentistas. Data desse período a iniciativa da Secretaria de Saúde de Pernambuco, em articulação com a Secretaria de Cultura, de realizar a 'caravana da cultura': utilizando a variada expressão da cultura popular pernambucana, percorreu todos os municípios do estado, levando informações sobre vacinas e saúde. Essas e outras experiências eram intercambiadas em seminários regionais e nacionais promovidos pelo Ministério da Saúde.

De fato, as campanhas de vacinação contra a poliomielite e todo aparato que envolveu sua consolidação demonstraram que a capacidade de mobilização de recursos extra-setoriais permitira ampliar em dez vezes o número de postos de vacinação. Além disso, a utilização de voluntários - que se reduziu de forma acentuada nos últimos anos tornou a vacina acessível a grandes contingentes populacionais, que, normalmente, não têm como chegar à rede de serviços.

No segundo dia nacional de vacinação, de 1990, a multivacinação foi retomada em todo o país. A despeito de opiniões contrárias e da experiência negativa anterior, a iniciativa demonstrou que, além de não comprometer a estratégia de erradicação da poliomielite, foi possivel recuperar os índices para as demais vacinas, tanto assim que, em 1990, as coberturas evoluíram para percentuais em torno de 90\% (Ministério da Saúde, 1998).

A estratégia é usada até hoje, oferecendo os estados e municípios outras vacinas nos dias nacionais de vacinação, inclusive para grupos populacionais como as mulheres em idade fértil ( 12 a 49 anos), visando a eliminação do tétano neonatal. Igual modelo de organização vem sendo adotado, sistematicamente, para a eliminação do sarampo, com campanhas em 1991 e 1995, bem como na vacinação de maiores de sessenta anos contra a gripe e de mulheres em idade fértil contra a rubéola. Tais operações também são utilizadas para finalidades como a busca de casos de hanseníase e a distribuição de vitamina A. O Brasil é exemplo e modelo para outros países. Técnicos brasileiros são convidados a prestar cooperação na montagem de estratégias de vacinação e mobilização de comunidades. 
Em 1989 foi registrado o último caso de poliomielite no Brasil, na cidade de Souza, na Paraíba. Em 1994 o país obteve o Certificado de Erradicação da Transmissão Autóctone do Poliovírus Selvagem.

$O$ relato que acabo de apresentar remete-nos àquela questão polêmica: campanha deseduca? Não se pode deixar de reconhecer que a comunicação, como fator essencial para a transformação da realidade, tem sido colocada, quase sempre, como reprodutora de ordens com intenção de levar os interlocutores a seguirem condutas 'corretas': Vacine seu filho!; Elimine criadouros de mosquitos!; Beba água limpa!; Não tome banho de rio! e Faça o exame preventivo do colo do útero! Na maior parte das vezes, no entanto, sem oferecer a contrapartida necessária para que a prática pretendida se concretize.

$\mathrm{Na}$ verdade, a assimilação de conhecimentos é um processo muito complexo. É muito maior do que o simples ato de falar ou o simples gesto de transmitir uma informação. Segundo Pilon (1995), "a educação não é uma coisa modesta. A educação é algo ambicioso. Não consiste em colocar remendo em tecidos rotos, mas em fazer um novo tecido, uma estampa diferente, em que os fios se entrelaçam numa nova configuração." Andrade (1997) afirma que "a ação dá sentido e significado à prática: ela implica a participação ativa do sujeito nos processos de exploração, seleção, combinação e organização das informações ... A informação, quando é mental ou afetivamente classificada como desconfortável pelo indivíduo, tende a ser ignorada; ao contrário, quando é considerada agradável, ela tende a ser incorporada".

Poder-se-ia afirmar que isso aconteceu com relação à vacinação?

O trabalho foi feito com esse objetivo. Buscou-se mobilizar pais e responsáveis por crianças menores de cinco anos, e havia necessidade de envolver profissionais, instituições, organizações e representações da comunidade. A definição do grupo-alvo foi o eixo orientador para que se estabelecessem conteúdos, materiais educativos, além de canais e meios de comunicação adequados à situação e à aprendizagem. A informação de massa adotou conteúdo simples e de fácil compreensão. Para os profissionais de saúde e outros protagonistas das campanhas, foram utilizados materiais educativos voltados para maior atenção à qualidade do serviço a ser prestado à população, contendo ainda informações específicas sobre a vacina e a estratégia de vacinação.

A televisão foi, e vem sendo, utilizada amplamente. Também têm grande importância o rádio fixo, o alto-falante volante e a rádio comunitária, assim como cartazes, jornais, folders e cartilhas. A tevê, no entanto, é o alvo principal dos críticos que condenam o modo como a população tem sido manipulada nesses anos de campanhas de vacinação.

Marcos Figueredo (2000) pode ajudar a reflexão sobre o papel da comunicação nas campanhas de vacinação: alude à 'teoria conspiratória' sobre a influência da mídia e afirma que estudos 
sistemáticos vêm demonstrando que este efeito é mais limitado do que se imagina, e mais complexo do que se supõe: "as mensagens emitidas pela mídia são seletivamente processadas pelo público e confrontadas com outras fontes". A influência da mídia na formação da opinião é, assim, "filtrada pela seletividade na recepção e pelo confronto com outras fontes", e seu poder depende da credibilidade das diversas fontes de informação: "quanto maior a credibilidade da fonte emissora de mensagens, maior a sua influência, pois a credibilidade na fonte orienta positivamente a seletividade na aquisição da informação e diminui a ansiedade do público na busca de outras fontes para o confronto".

A população brasileira continua a dar credibilidade aos chamamentos anuais para a vacinação contra a poliomielite e para outras vacinas. Também se mobiliza para o enfrentamento de outras situações, como o combate ao cólera, ao vetor da dengue etc. A rotina dos serviços de saúde, seja para vacinação, seja para outras medidas (pré-natal, acompanhamento do crescimento e desenvolvimento, tratamento da tuberculose ou hanseníase), ainda deixa a desejar em termos de respostas da população. É preciso buscar os motivos, pesquisar metodologias e técnicas de maior aproximação com a população, para que ela sinta estas ofertas como direitos de cidadania.

\section{REFERÊNCIAS BIBLIOGRÁFICAS}

Andrade, V. et al. 1997

Dias, J. C. P. 1986

Drumnond de Andrade, C. 1980

Figueredo, $\mathrm{M}$. 2000

Mendes, E. V. 1992

Ministério da Saúde 1998

Ministério da Saúde 1996

Ministério da Saúde 1988

Ministério da Saúde 1988
'O processo educacional na promoção de ações comunitárias em saúde'. Revista Brasileira de Cancerologia.

'Participação comunitária em programas de saúde'. Revista Brasileira de Malariologia e Doenças Tropicais.

A paixão medida.

$2^{a}$ ed., Rio de Janeiro, José Olympio.

'Mídia, mercado de informação e opinião pública'. Em

C. German et al., Informação \& democracia. Rio de Janeiro, Editora da Uerj.

O processo de construção do Sistema Único de Saúde: reflexões sobre uma agenda mínima para a Reforma Sanitária. OPAS. (mimeo.)

Programa Nacional de Imunizações - 25 anos.

Fundação Nacional de Saúde. Centro Nacional de Epidemiologia.

Assessoria de Comunicação Social. Projeto Nordeste.

Informação, educação e comunicação. Uma estratégia para o SUS.

A marca desenvolvimento e uso.

Secretaria Nacional de Ações Básicas de Saúde. Divisão Técnica de Divulgação.

Manual para campanhas de vacinação.

Secretaria Nacional de Ações Básicas de Saúde. Divisão Técnica de Divulgação. 
DEPOIMENTO DE CRISTINA M. VIEIRA DA ROCHA

Ministério da Saúde

1987

Ministério da Saúde 1986

Ministério da Saúde 1982

Ministério da Saúde 1981

Pilon, A. F. 1995

Pitta, A. M. da R. 1995

Sá, Carlos

Teixeira, M. G. 1999

Werthein, J. e Bordenave, J. D. (org.) 1981
Bases técnicas para a Erradicação da Transmissão Autóctone da Poliomielite. Secretaria Nacional de Ações Básicas de Saúde. Grupo Executivo do Plano de Ação para a Erradicação da Poliomielite.

A marca de um compromisso. Secretaria Nacional de Ações Básicas de Saúde. Divisão Técnica de Divulgação.

Educação em saúde na prevenção e controle de doenças transmissíveis Secretaria Nacional de Ações Básicas de Saúde. Divisão Nacional de Educação Em Saúde. (mimeo.)

Ação educativa nos serviços básicos de saúde. Secretaria Nacional de Ações Básicas de Saúde. Divisão Nacional de Educação em Saúde. Série Educação e Saúde, 2.

'Consórcio fortalece a promoção da saúde'.

Jornal da USP. São Paulo.

Saúde E comunicação: visibilidades e silêncios.

São Paulo, Hucitec/Abrasco.

Higiene e educação da saúde.

Serviço Nacional de Educação Sanitária (SNES).

'25 anos do Programa Nacional de Imunizações: Bahia'.

Em PNI-Babia, 25 anos de história. Secretaria de Saúde do Estado da Bahia.

Educação rural no terceiro mundo. Experiências e novas alternativas.

Rio de Janeiro, Paz e Terra. 